\title{
Post-Corporal Punishment Challenges Facing Eswatini Primary School Teachers When Disciplining Learners and the Necessary Counselling Services
}

\author{
Ruth N. Dlamini ${ }^{1}$, Moses Onyemaechi Ede ${ }^{2} \&$ Chinedu Ifedi Okeke ${ }^{3}$ \\ ${ }^{1}$ Faculty of Education, University of Eswatini, Kingdom of Eswatini \\ ${ }^{2}$ A Postdoctoral Fellow, Faculty of Education, University of the Free State, South Africa \\ ${ }^{3}$ Host \& Mentor, Faculty of Education, University of the Free State, South Africa \\ Correspondence: Moses Onyemaechi Ede, PhD, A Postdoctoral Fellow, Faculty of Education, University of the Free \\ State, South Africa.
}

Received: September 27, 2021

Accepted: December 3, 2021

Online Published: January 7, 2022

doi:10.5430/ijhe.v11n3p141

URL: https://doi.org/10.5430/ijhe.v11n3p141

\begin{abstract}
The purpose of this study was to explore post-corporal punishment challenges facing Eswatini primary school teachers when disciplining learners and the necessary counselling services. The research employed embedded research design using 48 primary teachers in the Hhohho region in the Kingdom of Eswatini. A purposive sampling was used to select the most accessible research participants. Instruments used were questionnaires and one-on-one interviews. Sixteen schools were selected. Data was collected and analyzed both quantitative and qualitatively. For analyzing data for questionnaires and observation, descriptive statistics such as frequencies and percentages were used and for analyzing data for interviews, thematic analysis was used. Findings show that teachers are facing challenges regarding learner discipline in post corporal punishment in primary schools. Teachers are confused and afraid of infringing learners' rights. Given the findings, some notable recommendations were highlighted.
\end{abstract}

Keywords: corporal punishment, discipline, primary school teachers, counselling services

\section{Introduction}

Corporal punishment is a sort of issue that involves direct infliction of ache at the bodily body (Moyo, Khewu \& Bayaga, 2014). However, it may additionally be taken past the bodily to emotional and mental domains, for example, verbal abuse and depravation of simple wishes like meals and using the toilet. In addition to corporal punishment having a poor impact on parent-infant relationships, it additionally encourages newbies to be emotional, in place of being goal thinkers.

While disciplinary practices form the general study room atmosphere, subject impacts college students' populations differently. The application of a few disciplinary practices has been observed adverse to instructional performance. With developing expertise approximately the dangerous outcomes of alienating college students from the faculty setting, new legal guidelines and processes are being established. Despite the new laws, schools continue to rely heavy on negative disciplinary practices (MacNabb, 2013). The study of "teachers disciplinary practices and their impact on learner behaviour in primary schools in the Hhohho Region, Kingdom of Eswatini', is important to the researcher because little attention has been placed on understanding the teachers disciplinary practices and their impact on learner behaviour in primary schools. The researcher is hoping that through this study teachers will understand the disciplinary practices and their impact on learner behaviour in primary schools.

Students' behaviour regularly poses demanding situations to teachers. Sometimes such behaviour reasons infection to the instructor coaching a massive elegance with various abilities. Sometimes the behaviour of positive kids disrupts the ordinary operation of the lecture room or faculty for a time. Acceptable behaviour is reinforcing in a faculty and lecture room weather that is supportive of fantastic behaviour. Classroom rules define acceptable behaviours and provide clearly defined expectations UNESCO (2015). Disruptive behaviour can be defined as behaviour which seriously upsets the normal running of the school (Marciniak, 2015).

Mumthan, Jouhar and Abdul (2014) argue that whilst kids are pushed through worry of punishment, they research actually to thrill the trainer and now no longer to accumulate capabilities and know-how for his or her personal 
development. Corporal punishment for this reason distorts a pupil's motivation and studying as the scholars is prompted through worry. Children who're corporal punished and emotionally abused broaden tension that reasons lack of attention and bad studying. In public colleges the usage of corporal punishment and different harsh disciplinary practices impacts each pupil in that school, such as folks who aren't individually subjected to hitting. Children who revel in or witness bodily violence will themselves broaden disruptive and violent behaviours, in addition worrying their classmate' studying in addition to their personal.

Psychologists argued that corporal punishment motives psychological damage, affects the conceitedness of learner and adversely influences academic achievement. Corporal punishment has been banned in over thirty states in the United States of America. Although the use of corporal punishment has been positioned to reason vital injuries and long lasting damage, twenty states had been despite the fact that the use of some form of corporal punishment in 2007. Two to a few million incidents of corporal punishment are anticipated to get up withinside the educational environment consistent with year, with critiques of over 20,000 university college students on the lookout for medical treatment (Save the Children, 2015). Agesa (2015) discovered out that the banning of corporal punishment elements to the requirement and importance of excessive first-rate measures to ensure discipline. This is what Somayeh (2013) refers to as excessive first-rate discipline.

In the abolition of what seemed to be walking for educators inside facet the past to maintain discipline, and at the same time implementing the duty to maintain discipline without equivalence is hard and frustrating. From the time beginners realised that corporal punishment changed into abolished, their misbehaviour multiplied and presently they appear to be out of control. Many colleges, in particular in Mafikeng place in South Africa, learner's misbehaviour is so vital that numerous educators take into account that the use of corporal punishment need to be frequent in colleges as quickly as more, because of the truth its abolition has left them without an effective strategies of implementing discipline. Managing learner behaviour has end up one of the most intricate and contested areas in colleges for the cause that banning of corporal punishment. Nyang'au (2013) pointed out that educators today face many challenges because they must check for weapons, maintain a safe and positive classroom climate and deal with disruptive behaviours. In addition, Emekako (2016) noted that dealing with challenging learner behaviour is demanding a great portion of teacher time, as the number of students with consistent behavioural problems appears to be increasing. The number of disciplinary actions taken by schools in response to less serious behavioural offenses has increased over time (Munthan, Jouhar \& Abdul 2014). The debate on the use of disciplinary practices and their impact on learners' behaviour ranges not only in the Kingdom of Eswatini, but also in various parts of the world. MacNabb (2014) has pointed out that many approaches to the control of the child are being advocated and implemented. Many of the approaches were a direct desire, but of late there has been a great emphasis in the avoidance of any sort of punishment not just corporal punishment.

It is believed that students have suffered bruises, abrasions, broken bones, whiplash and brain injury. It is also believed that through corporal punishment, some learners have even died. A study carried out by Ba-Saddick (2013) in Yemen, which involved 1,066 students who were 12-17 years olds from 8 schools revealed that $57.7 \%$ have been slapped at the face, overwhelmed at the head, had their hair pulled, their fingers crushed, had an item thrown at them and have been compelled to face withinside the sun. The Office of Civil Rights (2013) reviews that 2223, one hundred ninety faculty youngsters within side the United States acquired corporal punishment in the course of the 2006-2007 academic year with estimates that encompass up to a few million youngsters and 10,000 to 20,000 requiring scientific treatment. Reported scientific findings encompass abrasions, extreme muscle injury, sizable hematomas, whiplash harm and others which includes death.

A study conducted by UNICEF (2014) revealed that in Nepal, most teachers, students and parents accepted that beating and humiliating children is very common in schools. Some teachers argued for the necessity of severe punishment, insisting that without it, students inevitably become careless and disobedient. Some teachers argued that "We are forced to give severe punishment to students because it is the demand of the managing committee of the school, the parents and even the Ministry of Education". Most of the teachers use a range of physical methods of physical punishment, such as hitting the students against the walls or desks, forcing them to kneel on the rough surface with bare knees, locking them in the school toilets or forcing them to stand outside in the rain and slapping them hard on the cheeks.

Richard (2016) has mentioned that there have 4,556 instances of excessive corporal punishment of youngsters in Eswatini faculties during the last 4 years, as worldwide information enterprise mentioned. As these days as September 2015, a 17 year-vintage college scholar died after allegedly being crushed at college in Eswatini. The scholar reportedly had a seizure. In addition, Richard (2016) mentioned that during February 2015, the pinnacle 
trainer of 1 High School placed situated at the Hhohho location reportedly admitted giving 15 strokes to a shape 1 scholar for now no longer carrying a neck tie properly. Furthermore, Richard (2016) has mentioned that during March 2015, a number one college trainer in a single college became charged with inflicting grievous physical damage after allegedly giving two hundred strokes of the cane to a 12 year-vintage scholar on her buttocks and throughout her body. While corporal punishment has been practised for many centuries in South Africa and elsewhere in the world, it became entrenched in the classroom during the apartheid years (Agesa, 2015).

The abolition of corporal punishment in school, has presented a new challenge to the classroom, and teachers with respect to dealing with difficult behaviours. Most schoolchildren disciplining instances pronounced in colleges have raised issues approximately the protection of college students even as in school (Agesa, 2015). After the abolishment of corporal punishment in colleges in South Africa, a good number of educators felt helpless in managing learner indiscipline in learning settings. Agesa (2015) noted that stopping corporal punishment gives way for the adoption of various varieties of disciplinary strategies, however their effectiveness in curtailing destiny misbehaviour continues to be questionable. Teachers are nevertheless in a catch 22 situation of getting to locate powerful approaches of managing college students' misbehaviour in colleges even as on the identical time minding approximately college students' right. Therefore, this study was to determine the challenges educators face regarding learner discipline in post corporal punishment in primary schools in the Hhohho region.

\section{Method}

\section{Design}

The study employed descriptive survey and qualitative designs in this study.

\section{Participants}

The researchers recruited 48 participants (10\% of the population) consisted of head teachers and teachers of primary schools in the Hhohho region. That is $10 \%$ of 162 head teachers and $10 \%$ of 324 teachers were purposively sampled as participants for this study. Participants were drawn from selected schools which are under the Madlangempisi Branch of Eswatini National Association of Teachers (ENAT). There are 16 primary schools in the Madlangempisi Branch of ENAT. The schools are public schools in the rural area. Sixteen schools were selected as the study was to be an in-depth analysis about teachers' disciplinary practices and its impact on learners' behaviour in primary schools.

\section{Instruments for Data Collection}

The instruments used for collecting data were questionnaires and interviews.

Post-corporal punishment challenges Questionnaires: This is an open-ended questions and structured questions that measures post-corporal punishment challenges facing teachers and head teachers in disciplining schoolchildren. It was constructed by the researchers. There were two parts. One part targeted the head teachers and the other targeted the teachers. It is a four likert-type scale of strongly agree, agree, disagree and strongly disagree. The questionnaires were first tested on the selected sample of one school which was similar to the actual sample to be used in the study. The procedures used in the actual study or data collection were similar to the pilot one. Comments to be made by the piloted respondents were used to adjust and improve the instruments. The reliability of the instrument was obtained at a Cronbach's alpha coefficient of .85 . The instrument was deemed reliable since the obtained alpha coefficient (.85) was above the accepted .70

Interviews: The interview was a researchers' self-developed aimed at exploring and assessing post-corporal punishment challenges facing teachers and head teachers in disciplining schoolchildren. Interviews were scheduled for teachers only. The researchers used the one to one type of interview. To determine the reliability of the instruments, a pilot study was conducted in one school selected randomly from the public primary schools in the Hhohho region. After establishing validity and reliability of the instruments, the instruments were then administered in 16 public primary schools in the Hhohho region for the final data collection.

\section{Method of Data collection}

The administration of the 48 copies of questionnaires were executed the research team. The researchers went to the selected schools where teachers and head teachers completed the questionnaires in person. The process of distribution and retrieval of the questionnaire lasted for about seven days. Thereafter, the research team gathered the questionnaires for information analysis, after making sure that they were absolutely finished.

During the interview sessions, the researchers asked for consent from the principal to interview the teachers. The researchers interviewed the teachers personally. When the times were inconvenient for any participants due to 
schedule changes, permission was obtained from school administrators to conduct the interview at a time that was more convenient. The locations where the interviews took place were organised and set up prior to interview participants to ensure that the space was adequate, the lighting was sufficient and that the environment was quiet and conducive for interviewing. The interview questions were designed to the research questions. The responses were documented in several ways. The researcher recorded the interviews using tape recorder. The interviews were also recorded using paper and pencil.

\section{Method of Data Analysis}

Demographic data were analysed using frequency distribution and percentage. The data collected were analysed by the use of descriptive statistics and the information was presented in the narrative form.

\section{Results}

Table 1 presents the challenges faced by teachers in maintaining improved student behaviour. The responses given by the respondents on challenges they face in maintaining improved student behaviour included the following; not co-operating parents, teachers are not well trained on how to counsel students and some members of the community are against some of the disciplinary practices. Twenty-two educators $(46 \%)$ indicated that teachers were not well trained on how to counsel students. Fourteen educators (29\%) revealed that some members of the community were against some of the disciplinary practices. The finding of the study shows that most educators are not well trained on how to counsel students in primary schools.

Table 1. Challenges faced by teachers in maintaining improved student behaviour

\begin{tabular}{lllllll}
\hline Responses & H/Ts & \multicolumn{2}{l}{ Teachers } & \multicolumn{2}{l}{ Total } \\
\hline & $\mathbf{f}$ & $\mathbf{\%}$ & $\mathbf{f}$ & $\mathbf{\%}$ & $\mathbf{f}$ & $\mathbf{\%}$ \\
Parents are not co-operating & 2 & 12 & 10 & 31 & 12 & 25 \\
$\begin{array}{l}\text { Teachers are not well trained on how to } \\
\text { counsel students }\end{array}$ & 7 & 44 & 14 & 44 & 22 & 46 \\
$\begin{array}{l}\text { Some members of the community are against } \\
\text { some of the disciplinary practices }\end{array}$ & 7 & 44 & 8 & 25 & 14 & 29 \\
Total & $\mathbf{1 6}$ & $\mathbf{1 0 0}$ & $\mathbf{3 2}$ & $\mathbf{1 0 0}$ & $\mathbf{4 8}$ & $\mathbf{1 0 0}$ \\
\hline
\end{tabular}

Key: $\mathrm{H} / \mathrm{Ts}=$ Head Teachers

\section{Things that happen to the teachers if a learner is punished and is seriously injured}

Table 2 presents the teachers' responses on what happens to the teacher if a learner is punished and is seriously injured. The table demonstrates that 37 educators $(77 \%)$ revealed that they reported to the Head teacher and 9 educators $(19 \%)$ reported that teachers were expelled from the work if the learner is punished and seriously injured. This indicated that most teachers report to the head teacher if the learner is punished and is seriously injured.

Table 2. Teachers' responses on what happens to the teacher if a learner is punished and is seriously injured

\begin{tabular}{lllllll}
\hline Responses & H/Ts & \multicolumn{3}{c}{ Teachers } & \multicolumn{3}{c}{ Total } \\
\hline & F & $\mathbf{\%}$ & $\mathbf{f}$ & $\mathbf{\%}$ & $\mathbf{f}$ & $\mathbf{\%}$ \\
Nothing happens & 0 & 0 & 2 & 6 & 2 & 4 \\
Report to the head of school & 9 & 56 & 28 & 88 & 37 & 77 \\
Expelled from the profession & 7 & 44 & 2 & 6 & 9 & 19 \\
Total & $\mathbf{1 6}$ & $\mathbf{1 0 0}$ & $\mathbf{3 2}$ & $\mathbf{1 0 0}$ & $\mathbf{4 8}$ & $\mathbf{1 0 0}$
\end{tabular}

Key: $\mathrm{H} / \mathrm{Ts}=$ Head Teachers

The data gathered from respondents through interviews indicated that there are several challenges educators faced regarding learner discipline in post corporal punishment in primary schools in the Hhohho region. For examples; lack of respect towards the teachers, pupils' rights, parents not co-operating, parents are against some disciplinary practices and disciplining students is time wasting. 


\section{Learners are not respecting their educators}

Most participants revealed that students are not respecting their teachers. Most students are even chewing bubble gums and sweets while the teachers are teaching. For example, participant 1, a teacher at school A commented that:

"Learner indiscipline causes much stress in teachers. At times students are calling the teachers by names and some of the students are refusing to take any punishment if the teacher tries to discipline them. Some of the students use to laugh whenever a teacher is telling them to stop misbehaving."

In most cases students are assaulting the teachers. In that way some teachers end up leaving the teaching profession. Participant 7 at school D remarked that:

"Learners are assaulting the teachers; as a result most teachers are leaving the profession. In that way the results are seriously affected."

In addition, Participant 20, a teacher at school $\mathrm{J}$ revealed that:

"Due to students disrespect, students are bullying the others even in front of the teachers knowing that there is nothing the teacher can do".

\section{Students have rights}

Teachers are experiencing challenges due to the fact that learners have rights that protect them from any harmful discipline in schools, in that way educators are scared to discipline students because once the student is injured, the teacher will be expelled from the profession. For example, participant 5 , a teacher at school $\mathrm{C}$ remarked that:

"Banning of corporal punishment leads to a challenge to control the learners. More rights are given to the child who makes teachers unable to discipline them. Due to child's rights some teachers are not interested in disciplining students. Teachers are faced with a problem of trying to respect children's rights and at the same time finding adequate and meaningful measures to deal with learner indiscipline without infringing on their rights. Teachers feel powerless because the learners they teach have rights."

\section{Parents not co-operating with teachers}

Parent are not co-operating with the teachers in disciplining the students. Students are coming late at school, bullying others and destroying school property. The teachers used to call the parents to school concerning the student misbehaviour, but parents are refusing to come to school. Parents used to say they are busy and end up not coming to school".

In addition, participant 17 , a teacher at school I stated that:

"Parents are not co-operating; they are reluctant to cooperate with teachers in disciplining their children. If teachers ask the parents to help the learner to stop behaving in a bad manner, the parents tell the teachers that they must beat the learner because even at home they are tired of the learner behaviour.

\section{Parents are against some disciplinary practices}

Parents are against some of the disciplinary practices. For example, teachers use manual activity to discipline students and parents are complaining that it harms their children

According to participant 15 , a teacher of school $\mathrm{H}$ :

"Most parents are against some disciplinary practice. They suggest that their children will be dirty and they will get injured".

\section{Disciplining student is time wasting}

Most participants revealed that some of the disciplinary practices are demanding their time. Instead of teaching, teachers were forced to discipline the learners. Even if it is after school, the teachers should be with the students trying to monitor.

Participant 10 at school E asserted that:

"Time is wasted as the teachers are punishing students because instead of teaching, teachers discipline the students. At times the educators are forced to re teach a lesson if any student is suspended" 


\section{Discussion}

The research established that teachers were facing challenges regarding learner disciplinary problems in post corporal punishment in primary schools. Students were no longer respecting the teachers. Students were making noise, fighting each other and not coming to school. Students did as they wanted; they were no longer doing home works because they know that the teachers would not punish them. Teachers were confused and afraid of infringing upon learner rights. Teachers were no longer allowed to beat students. If a learner was seriously injured, parents could go to the police station and open a case against the teacher. Since the banning of corporal punishment, teachers do not know what to do to discipline the learners. Teachers were not well trained on how to counsel students. Some members of the community were against some of the disciplinary practices. Teachers were expelled from the work if the learner was punished and seriously injured.

In the context of this study, disciplining of student is a challenge encountered by teachers in the post corporal punishment era because it is time wasting. According to Nyang'an (2015) suspension from school led to loss of valuable learning time for learning time for the students. Makendano (2016) claimed that instructors have stated that they may be uncertain, pressured and frightened of infringing upon beginners' rights; pointing out that the over emphasis located on students' rights might also additionally reason an "I don't care attitude" and a loss of regard for the instructor's position within the classroom. According to Media (2012), if a learner is punished through the instructor and is critically injured, dad and mom can visit the police station and open a case in opposition to the instructor. Makendano (2013) affirms that a few different elements associated with the shortage of parental involvement in colleges that have an impact on field have been unmarried parented homes, a loss of parental control, the poor have an impact on of audiovisual, neighbourhood and community issues that have an impact on the house and values variations among the house and the college. Mestry and Khumalo (2012) argue that an energetic partnership among dad and mom may have a effective impact at the kids' behaviour. Mtsweni (2008) indicated that many dad and mom have been reluctant to co-operative with the academics in disciplining their kids. Makendano (2013) additionally found out that many mother and father have been now no longer concerned within the schoolchildren, inflicting negative results, excessive dropout quotes and the absence of field in class. Emekamo (2016) keeps that dad and mom are to be concerned in each a part of the schooling in their kids for you to take obligation of something final results in kids' conduct. In assist of this, Upindi, Mushhndja and Likando (2016) are of the opinion that mother and father have to really be concerned in all their kids' affairs, due to the fact while they may be concerned, the kids sense stable and therefore carry out better. Parents may have a super effect on their kids' behaviour through making sure that the beginners arrive at college on time, behave correctly.

\section{Recommendations}

Given the outcome of this study, the researchers suggested Guidance and counsellors should be assigned to all schools for full implementation of counselling services. With this, guidance and counselling programme would be often organised for the students in their respective schools. Corporal punishment should be reinstated because the study found that teachers resort to its when dealing with certain forms of misbehaviour although its use should be controlled by the Ministry of Education and Training. Teachers should be given the rights to use corporal punishment to protect themselves against misbehaving students to gain control of a dangerous weapon.

\section{Limitations of the Study}

The study was restricted to primary school teachers in the Hhohho region of Eswatini. The researcher would have liked to include all primary school teachers in all the four regions of Eswatini in order to justify generation of the findings to the entire population of primary school teachers in the Kingdom of Eswatini. Time and financial constraints also limited the researcher.

\section{References}

Agesa, R. I. (2015). Effectiveness of alternative disciplinary strategies used in secondary Schools in Starehe Division, Nairobi County, Kenya. Unpublished master's dissertation. Nairobi, Kenya: Department of Education Management, Policy and Curriculum.

Emekako, R. (2016). Disciplinary measures for learners in secondary schools: An evaluation of a district in the North West Province. Pakistan Journal of Social Sciences, 13, 64-72.

MacNabb, A. (2013). Disciplinary practices in the elementary School setting. Trinity College, Hartford, South, South Africa. Unpublished master's dissertation. Hardford, South Africa: Department of Education. 
Makendano, A. (2016). Investigating teachers' experiences of learner discipline senior secondary schools, Zambezi Region, Namibia, University of South Africa. Unpublished master's dissertation. Zambezi, Nairobi: Department of Education Management.

Marciniak, A. (2015). Effective ways of dealing with discipline problems when teaching adolescent learners. The State School of Higher Professional Education in, Poland, 7, 53-72.

Media, M. (2012). Positive discipline and classroom management. Centre for justice and crime prevention and the department of basic education, Pretoria, Cape Town. Unpublished master's dissertation. Pretoria, Cape Town: Department of Basic Education.

Moyo, G., Khewu., \& Bayaga, A. (2014). Disciplinary practices in schools and principles of alternative to corporal punishment. South African Journal of Education, 34(1), 1-13. https://doi.org/10.15700/201412120952

Mumthas, N. S., Jouhar, M., \& Abdul, G. (2014). Student and teacher perception of disciplinary practices: Types, reasons, consequences and alternatives. Guru Journal of Behavioural and Social Science, 2(4), 301-308.

Nyang'au, E. (2013). Effects of disciplinary strategies on students' behaviour in public secondary schools in Matungula District, Nairobi country, Kenya. Unpublished maser's dissertation. Nairobi, Kenya: Department of Education.

Richard, R. (2016). Swazi School “torture” Students. Retrieved March 31.2016 from blog spot.com/2011/09/swazi school-tortures-students.html

Save the children. (2015). Positive discipline in everyday teaching. A Primer for Filipino Teachers Department of Education. Unpublished draft. E-net Philippines.

UNESCO. (2015). Positive discipline in the inclusive, learning-friendly classroom. A guide for teachers and teacher education. United Nations Educational, Scientific and Cultural Organization.

United Nations Children's Fund. (2010). Child Disciplinary Practices at Home: Evidence from a range of low and middle-income countries, NY: UNICEF.

Upindi, N., Musshaandja, J., \& Likando, G. (2016). Addressing factors that contribute to indiscipline in secondary schools in Namibia: A Case Study. Unpublished master's dissertation. Nairobi, Kenya. Department of Education and Management.

\section{Copyrights}

Copyright for this article is retained by the author(s), with first publication rights granted to the journal.

This is an open-access article distributed under the terms and conditions of the Creative Commons Attribution license (http://creativecommons.org/licenses/by/4.0/). 